\title{
Research on the Reform of Physical Education in Colleges and Universities Based on the Concept of Lifelong Sports
}

\author{
Chen Hui, Song Haiquan \\ Guangzhou Huali Science and Technology Vocational College, Guangzhou, China, 511325
}

Keywords: Lifelong physical education, college physical education, teaching reform, innovation, problems.

\begin{abstract}
The educational concept of lifelong physical education is not just some new concept. Lifelong physical education refers to physical exercise accompanied by lifelong and ubiquitous. College physical education is an important part of lifelong physical education, but there are many problems in college physical education. This paper mainly introduces some problems in college physical education and analyzes the problems, and finally finds out ways to solve these problems. This will play a very important role in the development of college physical education, the strengthening of the people's physique, and the enrichment of people's spare time life. Whether in the distant ancient times or in the distant future, it is necessary to attach importance to life-long physical education and deeply experience the spirit of life-long physical education, which has a far-reaching impact on physical education in colleges and universities.
\end{abstract}

\section{Introduction}

Colleges and universities are the institutions of higher learning to train talents, the ivory tower expected by the students, and a strong physique is the soul of talents, so physical education in Colleges and universities is very important. Since the education reform has played an important role in the development of college physical education, there are still a series of problems. At present, the most important thing is to find out the existing problems, and analysis the problems and find out the solution to the problem, so that the development of physical education in colleges and universities can help students to strengthen the people's physique, to enrich the people's amateur life and to make people's life happy. ${ }^{[1]}$.

\section{Connotation of lifelong sports concept}

The concept of life-long sports education was not born recently. As early as the 1960, Paul Langland, a famous French scholar, put forward the concept of "life-long sports" in Japan, which is the same as life-long sports. Lifelong physical education is a part of life-long education that people have long respected, and it is gradually recognized by people in life. The concept of lifelong physical education mainly refers to: first, learning physical education is not only in school, not only in the physical education classroom, physical education should be everywhere in life at work, 
people from the beginning of the birth to the death, all have the awareness of physical education, in addition to learning in the classroom in the learning era of physical education, life and direction in peacetime After the society, we should also strengthen physical training at any time, consciously study physical education, whether subconscious or unconscious exercise is physical education, which should be accompanied by a person's lifetime; second, physical education should have a clear goal, in different stages and places, as far as possible for people to create participants. Opportunities for educational activities. Lifelong sports emphasize lifelong, in the process of physical exercise, people not only get a healthy body, but also can enhance people's self-confidence, but also cultivate people's self-control ability. At the same time, the process of exercise will produce pleasant dopamine, so enhance physical exercise makes people feel happy, open-minded, enhance their ability to live and work. Whether in the distant ancient times or in the distant future, we should attach importance to life-long physical education and deeply experience the spirit of life-long physical education, which has a far-reaching impact on Physical Education in Colleges and universities $^{[2]}$.

\section{The importance of lifelong sports concept}

The concept of lifelong sports is very important, so we should set an example of lifelong sports from ourselves. Lifelong sports make people's comprehensive quality develop in an all-round way. Lifelong sports can also be used as a form of entertainment and leisure to meet people's amateur life needs. Strong physique is the soul of the nation's survival, which is beneficial to society. Development is also of great significance ${ }^{[3]}$,The importance of lifelong sports is shown in Figure 1.

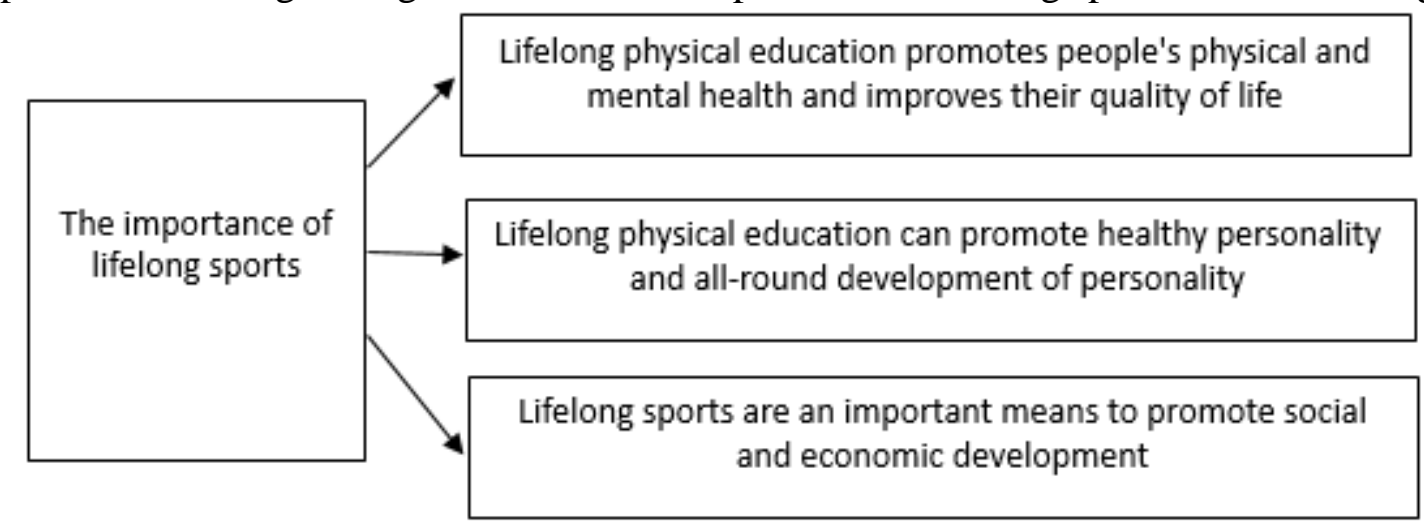

Figure 1 The importance of lifelong sports

\subsection{Lifelong physical education promotes people's physical and mental health and improves their quality of life}

Physical exercise on the surface seems to exercise the body, is the respiratory system, cardiovascular system, muscle function, etc., but in fact, not the same time, exercise also makes people's mind has been greatly satisfied, conducive to physical and mental development, thinking expansion and intellectual development. ${ }^{[4]}$.

\subsection{Lifelong physical education can promote healthy personality and all-round development of personality}

The form of physical exercise is rich and colourful. People feel different in different forms of physical exercise. Some relax, some tense and some relax. It makes people's body adapt greatly to 
various situations. It also stimulates people's desire to exercise. Some

Thrilling exercise is to let people know how to cherish life and cherish life. Physical exercise is not only a physical exercise, but also a powerful tool to promote healthy personality and personality development in an all-round way.

\subsection{Lifelong sports are an important means to promote social and economic development}

2008 is an unforgettable year for the Chinese people. The launching of the Beijing Olympic Games makes people remember it vividly. Sports has become a cause and an important tool to promote the development of national economy. It is precisely because the country is aware of the enormous economic value contained in sports that the 2008 Olympic Games and Paralympic Games have been held. This is a great contribution to the national economy. The rapid progress is great, and it is very beneficial to enhance our position in the world. Therefore, we advocate the concept of lifelong sports is not only in line with the national conditions of contemporary countries but also in line with the current situation of the development of the contemporary world. ${ }^{[5]}$.

\section{Problems in the current situation of physical education in Colleges and Universities}

\subsection{The main position of students is not clear}

The development of physical education today is not smooth sailing, but also accompanied by a lot of problems, especially in college physical education, as in other courses, teachers still use the teaching method of indoctrination, the knowledge blindly imposed on students, students in the end have a good understanding, whether there is integration, teaching. Teachers do not care at all, they only care about whether their teaching tasks have been completed, only concerned about whether their examination results are qualified, when the results are not ideal will not do reflection, but only unilateral criticism of students, may lead to student's dislike learning physical education. Originally, students were full of curiosity and confidence in sports, but under the irresponsible leadership of teachers, students gradually lost confidence, no initiative to learn the idea, or even have truancy. Many teachers, regardless of the degree of acceptance of students, do not have good feedback to understand the true acceptance of students, in many students have not accepted the situation, began to teach the next teaching task, students were dragged away by teachers, learning more and more hard, more and more tired, teachers are tired of teaching, students hate sports Learning, let alone forming the concept of lifelong physical education, which is contrary to the purpose of physical education teaching in Colleges and universities. Teachers neglect that students are the important information of the main body of physical education and cannot teach sports well.

\subsection{Teaching content is "many and old" teaching methods and methods are slow to update}

Teaching content and means are important parts of physical education, but most of the current college physical education textbooks are inconsistent, the various schools of physical education textbooks, physical education teaching methods are different, there are many schools still use many years ago has been outdated teaching materials and methods, so that students do not mention physical education. Interest. And there is a common problem in the current physical education textbooks, that is, the knowledge is too scattered, there is no focus, teachers cannot understand the textbooks, cannot grasp the focus of the textbooks, the teaching content is chaotic, students are also confused, what teachers teach them to learn, without their own ideas. There is also a phenomenon that many schools lower grade PE teaching content and higher-grade PE teaching content repetition, to the higher grade, still follow the teaching method of lower grade, follow the teaching content of 
lower grade, repetition to teach, which also makes students no interest in sports learning, lose confidence in them. I prefer to be free to study under the guidance of teachers. Even some schools do not have physical education materials, or even cancel the physical education curriculum, these are universal, is hindering the development of physical education. Teachers 'reasons and teaching content restrictions lead to bad teaching results, students do not like sports learning, so it is difficult to form the concept of lifelong sports.

\section{The path of College Physical Education Reform under the background of lifelong sports}

\subsection{Developing students' interest in Physical Education}

The ways of physical exercise are various and endless. With the economic progress and social development, there are more and more kinds of physical exercise equipment. Under such circumstances, it is much easier to stimulate students 'interest in physical education. In P. E. class, aiming at strengthening physical fitness, aerobics, hip-hop, rock climbing, skiing and other forms of teaching can be used together to better stimulate students 'interest in learning. In addition, in addition to these teaching content, teaching mode should also be varied, so that students can germinate a good feeling of learning sports, willing to learn, consciously to learn. In addition, we should set up teaching according to students 'interests and hobbies, attract students' attention, enable students to fully display their own advantages, and truly feel the pleasure brought by sports, to love physical exercise and establish the concept of lifelong sports.

\subsection{Cultivating students' ability to engage in sports independently}

College physical education is only a small part of lifelong sports, but it is a very important part. Colleges and universities provide students with a superior exercise environment and learning environment, college physical education to students basic sports knowledge, sports hygiene and sports health care, but these are far from enough, but also must teach students the ability to integrate theory with practice, independent handling of affairs, because students cannot always be in the school, there is always going to society One day, therefore, it is more important to teach them the ability of physical exercise, so that they can do better physical exercise in their future work and study, and truly achieve lifelong physical exercise.

\section{Conclusion}

Physical education reform in colleges and universities should determine the students 'main position in teaching activities. Students' interest in sports can be concerned. As lifelong sports concept gets into the teaching of physical education in colleges and universities, students can enhance the scientific understanding of sports. To make students get good sports habits, colleges and universities need to strengthen students 'awareness of life-long sports through publicity, and through the transformation of teachers' teaching concepts. Reforming of teaching methods and teaching content, and organizing various forms of body Sports activities, by this way, the idea of lifelong physical education can be effectively implemented in college physical education.

\section{References}

[1] Shao Linhai. Research on the professional development of physical education teachers in local universities [D]. Northeast Normal University, 2016.

[2] Hou Ying. Research on the current situation of public physical education curriculum reform in Chongqing universities [D]. Chongqing University, 2016. 
[3] Cen Hailong. Research on the Reform and Innovation of Physical Education Teaching in Colleges and Universities under the Background of Lifelong Sports [J].Contemporary Sports Science and Technology, 2015,5(17): 1-2.

[4] Mao Zhihai. The implementation of College Physical Education Model Based on lifelong sports concept [J].Contemporary sports science and technology, 2012, 2 (05): 40-41.

[5] Li Dan. Research on the Curriculum Design and Implementation of Sports Humanities Based on Teacher Professional Development [D]. Southwest University, 2011. 